\title{
Decision to delivery interval in emergency cesarean section and its association with perinatal outcome
}

\author{
Fareha Khatoon ${ }^{1}$, Amrita Singh ${ }^{2}$, Sumaiya Shamsi ${ }^{3}$, Ayesha Ahmad ${ }^{4}$, Nikunj Teotia ${ }^{5}$ \\ ${ }^{1,4}$ Associate Professor, ${ }^{2}$ Assistant Professor, ${ }^{5}$ Resident, Department of Obstetrics and Gynaecology, Era's Lucknow \\ Medical College and Hospital, Sarfarazganj, Lucknow, Uttar Pradesh, India. ${ }^{3}$ Assistant Professor, Department of \\ Paediatrics, Era's Lucknow Medical College and Hospital, Sarfarazganj, Lucknow, Uttar Pradesh, India
}

A B S T R A C T

Background: Decision to delivery [DDI] interval is the time interval between decision for caesarean section [CS] and delivery of baby. The ideal DDI for emergency CS is not known; there is controversy over the best DDI to avoid preventable perinatal morbidity and mortality. Aims and Objectives: This study was conducted to find out the DDI we could achieve for Category-1 and Category-2 CS and evaluate our findings against the recommendations by National Institute for Clinical Excellence [NICE]. We also studied the association of DDI with perinatal outcome and explored the reasons for prolongation of DDI. Materials and Methods: This was a prospective study conducted over a period of 6 months. All women who underwent CS and meeting the inclusion criteria were recruited for the study. DDI was calculated as the time interval between decision making and delivery of baby, in minutes [min]. Data was collected for maternal socio-demographic variables, CS indication and complications and perinatal outcome. Analysis was done using SPSS version 21.0. Results: Ninety out of one hundred eighty-one CS was evaluated. Cases were grouped as Group I [including cases where we could achieve the recommended DDI] and Group II [including cases where we could not achieve the recommended DDI]. The average DDI was 55.04 min for category- 1 and 55.13 for category-2 CS. For Category-1 CS, all the cases qualified for entry into Group II because we could not achieve a DDI of 30 min. For Category-2 CS there were 22 cases in Group I and 14 cases in Group II. There was no difference in perinatal outcome between the groups. Conclusion: It was not feasible to achieve the $30 \mathrm{~min}$ DDI for Category-1 CS in the present study. The DDI of 30-75 min for Category- 2 could be achieved in $61.11 \%$ cases. The most common reason for failure to achieve the recommended DDI was related to issues with anaesthesia in the pre-operative room as well as inside the theatre in the pre-induction phase. Delay in category-2 CS was not associated with poor perinatal outcome.

Access this article online

Website:

http://nepjol.info/index.php/AJMS DOI: 10.3126/ajms.v12i8.36316

E-ISSN: 2091-0576

P-ISSN: 2467-9100

Copyright (c) 2021 Asian Journal of Medical Sciences

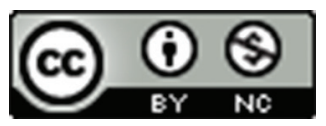

This work is licensed under a Creative Commons Attribution-NonCommercial 4.0 International License.

Key Words: Decision to delivery interval; Emergency cesarean section; Category 1 cesarean section; Category 2 caesarean section

\section{INTRODUCTION}

Decision to delivery interval [DDI] is defined as the time interval [in minutes] between decision for cesarean section [CS] and delivery of baby. A pragmatic balance of DDI to ensure good perinatal outcomes is still investigational. National Institute of Clinical excellence [NICE] recommends a DDI of 30- and 30-75 minutes [min] for Category 1 and 2 CS respectively to avoid preventable perinatal morbidity and mortality. ${ }^{1}$ However, this DDI is difficult to achieve in a large majority of low- as well as good-resource settings. ${ }^{2-4}$

Many investigators have questioned this recommendation due to lack of evidence on the subject. ${ }^{5,6}$ Others have found that in resource constrained clinical settings, the DDI 
suggested by NICE is achievable in less than $3 \%$ of cases. ${ }^{7.8}$ Nair et al., ${ }^{9}$ and Singh et al., ${ }^{10}$ observed that not only is this DDI impractical to achieve, but a delay upto $15-30 \mathrm{~min}$ does not have a significant impact on perinatal outcome. Dunn et al., ${ }^{11}$ also concluded that a shorter DDI does not ensure improvement in perinatal outcomes.

The present study was planned to assess the feasibility of achieving the DDI recommended by NICE for Category 1 - and 2-CS and its association with perinatal outcome. As a secondary outcome measure, we planned to investigate the common causes of failure to achieve the DDI.

\section{MATERIALS AND METHODS}

This was a prospective project conducted over a period of six months in the department of Obstetrics and Gynaecology at Era's Lucknow Medical College and Hospital. The study was approved by the institutional ethics committee. Data collection was carried out from September 2019 till February 2020. All women during this period, undergoing category 1- or 2- CS, at or after 37 weeks gestation and using spinal anaesthesia $[\mathrm{SA}]$ were recruited for the study after informed consent. Women with fetal anomalies and antenatal uterine demise were excluded from the study.

Decision for CS was taken by the senior resident on duty in consultation with the Consultant, on the basis of available clinical information. The time when decision was finalized and the Category of CS according to indication was recorded in the case file. Indications were classified in accordance with NICE recommendation. Emergency CS [ECS] were either classified as Category 1 when there was immediate threat to the life of mother and/or fetus, or Category 2 when there was maternal and/or fetal compromise that was not immediately life threatening.

DDI was calculated as the time interval between decision making and delivery of baby. This continuum was further divided into three intervals.

- Interval I [A-B]: Decision by obstetric team [A] and transfer of patient to operation theatre $[\mathrm{OT}][\mathrm{B}]$.

- Interval II [B-C]: Arrival of the patient in OT [B] to induction of anesthesia [C].

- Interval III [C-D]: From anesthesia induction [C] to delivery of baby[D].

A structured proforma was used to note maternal sociodemographic data, DDI and causes of delay, indication for CS, APGAR score, NICU admission and hospital stay. The time of receiving the patient in the post-operative ward was noted, and hospital stay calculated from that time.
A prolonged hospital stay was defined as admission in the hospital for more than 4 days.

\section{Statistical analysis}

Relevant data was entered in MS excel and SPSS version 21.0. We assessed data normality by Kolmogorov-Smirnov test. The subjects were grouped into two groups [Group I and II depending on whether we were successful in achieving the recommended DDI or not, respectively]. Perinatal complications were presented as number [proportion] and compared using Chi square test. All time intervals including DDI, age and BMI were expressed as mean +/- SD and compared using student $\mathrm{t}$ - test or analysis of variance as appropriate. Association of perinatal outcome with DDI categories [30 $\mathrm{min}, 30-75 \mathrm{~min}$, and $>75 \mathrm{~min}$ ] was calculated using Chi square test and Student $t$-test. A p-value $<0.05$ was considered statistically significant.

\section{RESULTS}

A total of 181 emergency CS were performed in the study period. $91 \mathrm{CS}$ were excluded as they did not fulfill the inclusion criteria. Out of $90 \mathrm{CS}$ included in the final analysis, 54 were Category- 1 and 36 were Category- 2 on the basis of indications (Table 1).

The average age of subjects was $27+/-4$ years and BMI was $24+/-3$. The most common indication was fetal distress and negative consent for trial of labour after CS [TOLAC] for Category-1 and 2- CS respectively.

The mean DDI was $55.04+11.17$ min for Category- 1 and $55.13+11.34 \mathrm{~min}$ for Category-2 CS (Table 2). There was no difference in the achievable DDI between the two groups. The shortest DDI was achieved for severe pre eclampsia with impending eclampsia and poor BISHOP score [37.62 min]; the longest DDI was for previous CS with negative consent for TOLAC [71.29 min].

Table 3 compares the perinatal outcome between the study groups. There was no significant difference in the outcomes for babies in the two groups. We could not compare Category-1 CS performed within stipulated time with those exceeding it because we could not achieve recommended DDI for any Category-1 CS. When Category 2 CS was divided into those who could be performed within the time frame suggested vis-a-vis those CS who had a delayed DDI, no difference was found with respect to neonatal outcome.

The reasons for delay in DDI are shown in Table 4. Nonavailability of investigations and delay in spinal anesthesia were found to be the main causes of delay accounting for $30.26 \%$ CS in each group. 


\section{DISCUSSION}

The present study was conducted to investigate if it is feasible to achieve the DDI recommended for Category 1- and 2- CS at a tertiary care hospital in the context of a developing country. This is an especially pertinent question for resource constrained settings, where, in the best of

\begin{tabular}{|c|c|c|c|c|}
\hline Indication & Number & $\begin{array}{c}\text { Percentage } \\
{[\%]}\end{array}$ & Mean & SD \\
\hline \multicolumn{5}{|l|}{ Category 1} \\
\hline Fetal distress & 37 & 41.11 & 58.13 & 11.71 \\
\hline cord prolapse & 1 & 1.11 & 51.32 & \\
\hline Obstructed labour & 3 & 3.33 & 63.89 & 6.34 \\
\hline $\begin{array}{l}\text { Deep transverse } \\
\text { arrest }\end{array}$ & 3 & 3.33 & 53.57 & 7.41 \\
\hline Scar tenderness & 10 & 11.11 & 49.19 & 4.82 \\
\hline Total & 54 & 60 & & \\
\hline \multicolumn{5}{|l|}{ Category 2} \\
\hline $\begin{array}{l}\text { Negative consent } \\
\text { for TOLAC }\end{array}$ & 12 & 13.33 & 71.29 & 12.47 \\
\hline Failed induction & 3 & 3.33 & 48.98 & 5.78 \\
\hline $\begin{array}{l}\text { Pre eclampsia } \\
\text { with impending } \\
\text { eclampsia with } \\
\text { poor BISOP }\end{array}$ & 6 & 6.67 & 37.62 & 8.26 \\
\hline Others & 15 & 16.67 & 54.33 & 6.93 \\
\hline Total & 36 & 40 & 55.10 & 11.26 \\
\hline
\end{tabular}

\begin{tabular}{|c|c|c|c|c|c|c|}
\hline Category & Mean & & SD & & $t$ test & $p$ value \\
\hline $1[\mathrm{~N}=54]$ & 55.04 & & 11.17 & & 0.01 & 0.98 \\
\hline \multirow{4}{*}{$2[\mathrm{~N}=36]$} & 55.13 & & 11.32 & & & \\
\hline & \multicolumn{4}{|c|}{ Delay } & Chi & $p$ value \\
\hline & \multicolumn{2}{|c|}{ Yes } & \multicolumn{2}{|c|}{ No } & & \\
\hline & $\mathbf{N}$ & $\%$ & $N$ & $\%$ & & \\
\hline $1[\mathrm{~N}=54]$ & 54 & 100 & 0 & 0 & 7.93 & $<0.01^{*}$ \\
\hline $2[\mathrm{~N}=36]$ & 22 & 61.11 & 14 & 38.89 & & \\
\hline
\end{tabular}

circumstances we might not be able to hasten DDI due to system limitations.

The present study had a total of 181 CS out of which 54 qualified for Category 1 CS and 36 for Category 2 CS. Our average DDI was $55.04 \mathrm{~min}$ and 55.13 for Category 1 - and 2- CS respectively. In none of the cases were we able to achieve a DDI of $30 \mathrm{~min}$ for Category 1 CS. Radhakrishnan et al., ${ }^{12}$ collected data on 275 CS cases and found a mean DDI of 183.24 minutes [122+/- 89 minutes for Category $1 \mathrm{CS}]$. They concluded that in the context of a developing nation, a more reasonable time frame would be better suited for ECS. Brandt et al., ${ }^{13}$ did a retrospective study in a Germany, on 437 women who underwent CS and found that they could adhere to a DDI of 20 minutes in $98.7 \%$ cases and had a mean DDI of 7.66 minutes. However, the same parameters would not be appropriate in the context of a resource limited country. Interestingly, within the same setting, the DDI was significantly prolonged outside core working hours. All the ECS in the study were done using general anesthesia [GA] whereas in the present study, all the ECS were done under SA; this would clearly have an effect on the DDI. At our institute, we perform rapid sequence SA for most of the Category-1 CS. However, at times we are constrained to use multiple attempts at SA, despite the existing policies. Besides better perinatal side effect and complication profile, due to discrepancy in manpower and workload, it is not possible in our situation to administer GA for ECS as a routine. The same infrastructural [including equipment] and manpower limitations would probably be seen in other low resource settings.

In a review, Rashid et al., ${ }^{14}$ observed that stringent adherence to a DDI of $30 \mathrm{~min}$ for Category $1 \mathrm{CS}$ is very difficult to achieve in regular practice. They further commented that the pressure of adhering to the $30 \mathrm{~min}$ DDI can in fact have a negative impact on feto-maternal outcomes

Table 3: Perinatal outcome

\begin{tabular}{|c|c|c|c|c|c|c|c|c|}
\hline \multirow[t]{3}{*}{ Variables } & \multicolumn{4}{|c|}{ Delay Category II [36] } & \multicolumn{4}{|c|}{ Delay Category $1[54]$} \\
\hline & \multicolumn{2}{|c|}{ Group II [14] } & \multicolumn{2}{|c|}{ Group I [22] } & \multicolumn{2}{|c|}{ Group II [0] } & \multicolumn{2}{|c|}{ Group I [54] } \\
\hline & $\mathbf{N}$ & $\%$ & $\mathbf{N}$ & $\%$ & $\mathbf{N}$ & $\%$ & $\mathbf{N}$ & $\%$ \\
\hline \multicolumn{9}{|c|}{ Prolonged Hospital Stay } \\
\hline Yes & 3 & 21.43 & 6 & 27.27 & 0 & 0 & 8 & 14.81 \\
\hline \multirow[t]{2}{*}{ No } & 11 & 78.57 & 16 & 72.73 & 0 & 0 & 46 & 85.19 \\
\hline & \multicolumn{2}{|c|}{ Chi square: 0.16} & \multicolumn{2}{|c|}{$P$ value:0.69 } & & & & \\
\hline Yes & 5 & 35.71 & 7 & 31.82 & 0 & 0 & 25 & 46.30 \\
\hline \multirow[t]{2}{*}{ No } & 9 & 64.29 & 15 & 68.18 & 0 & 0 & 29 & 53.70 \\
\hline & \multicolumn{2}{|c|}{ Chi square: 0.06} & \multicolumn{2}{|c|}{ Chi square: 0.81} & & & & \\
\hline \multicolumn{9}{|c|}{ Neonatal death } \\
\hline Yes & 0 & 0 & 1 & 4.55 & 0 & 0 & 6 & 11.11 \\
\hline \multirow[t]{2}{*}{ No } & 14 & 100 & 21 & 95.45 & 0 & 0 & 48 & 88.89 \\
\hline & \multicolumn{2}{|c|}{ Chi square: 0.11} & \multicolumn{2}{|c|}{ Chi square: 0.73} & & & & \\
\hline Total & 14 & 100 & 22 & 100.00 & 0 & 0 & 54 & 100 \\
\hline
\end{tabular}




\begin{tabular}{|c|c|c|c|c|c|}
\hline \multirow[t]{3}{*}{ Reason } & \multicolumn{4}{|c|}{ Average delay time } & \multirow{3}{*}{$\begin{array}{c}\text { Total } \\
\mathbf{N}\end{array}$} \\
\hline & \multicolumn{2}{|c|}{ 1. $-60 \mathrm{~min}$} & \multicolumn{2}{|c|}{$>60 \mathrm{~min}$} & \\
\hline & $\mathbf{N}$ & $\%$ & $\mathbf{N}$ & $\%$ & \\
\hline $\begin{array}{l}\text { Unavailability of } \\
\text { investigation }\end{array}$ & 11 & 47.8 & 12 & 52.2 & 23 \\
\hline $\begin{array}{l}\text { Non-availability of OT } \\
\text { technician }\end{array}$ & 1 & 25 & 3 & 75 & 4 \\
\hline Ongoing Previous Surgery & 3 & 100 & 0 & 0 & 3 \\
\hline Giving Spinal Anesthesia & 12 & 52.17 & 11 & 47.83 & 23 \\
\hline Obtaining Consent & 6 & 40 & 9 & 60 & 15 \\
\hline Shifting to OT & 4 & 50 & 4 & 50 & 8 \\
\hline Total & 37 & 48.6 & 39 & 51.4 & 76 \\
\hline
\end{tabular}

by compromise on asepsis, surgical technique, antibiotic prophylaxis, omission of bladder catheterisation etc.

In our analysis, the maximum delay occurred at interval II i.e. from arrival of patient in the OT to induction of anesthesia [30.26\%]. The most common reason for delay was non- availability of investigations [30.26\%]. Other reasons included delay in shifting the patient to OT, delay in consent, delay in availability of staff because of another surgery and multiple attempts at spinal anesthesia. Radhakrishnan et al., ${ }^{12}$ found non-availability of OT as the most important cause of delay, which would be relevant in their settings of a tertiary care government medical college with a massive workload of patients. Similar to our observations, Yakasai et al., ${ }^{15}$ found that the most important causes of failure to achieve optimal DDI were related to anesthesia.

There is a need for identifying obstacles responsible for delay at various levels and addressing such issues in order to decrease the overall DDI. Studies have suggested locating the operating room near delivery room, availability of OT staff along with obstetrician and anaesthesiologist along with an effective team work can effectively reduce the overall interval.

The present study did not find an increased risk of adverse perinatal outcome with an increase in DDI for Category 1 CS. Since we could not perform Category 1 CS within $30 \mathrm{~min}$, we were not able to compare outcomes with those cases that were able to achieve the recommended DDI. Many investigators have found similar observations. Yakasai et al., ${ }^{15}$ found that despite a delay of $>30 \mathrm{~min}$ in $87 \%$ cases, about $83.4 \%$ of the cases had a good fetomaternal outcome. Boriboonhirunsarn et al., ${ }^{16}$ found a DDI of $>30 \mathrm{~min}$ for Category $1 \mathrm{CS}$ in $93.4 \%$ of cases and noted no significant difference among groups relative to birth weight, birth asphyxia and NICU admission.

There were 6 neonatal deaths in the present analysis. Out of these, 4 mothers had CS for fetal distress, and 2 had scar tenderness. While FD was the most common indication of Category-1 overall, out of 37 babies, only 4 died. It could be that these babies were already compromised in the antenatal period and prolongation of DDI was not the only reason for fetal demise. One CS was done for cord prolapse had a DDI of 51.32 min; the baby still had a good outcome. Therefore, it becomes very difficult to categorize the DDI when correlated with fetal outcome. We feel that more research is required in this area to better define a DDI that has global applicability and is optimized for usage especially in the context of resource limited settings.

\section{Limitations of the study}

Our study is limited by numbers and the absence of maternal outcomes in terms of surgical site infection, surgical blood loss, urinary tract infections, post-operative recovery, etc. We did try to rule out bias related to anaesthetic methods by including only SA. However, GA is recommended for Category-1 CS, hence DDI has been determined accordingly. Besides, maternal factors such as BMI, previous surgery and external factors such as time of surgery [day/night] would also affect DDI.

\section{CONCLUSION}

It was not feasible to achieve the $30 \mathrm{~min}$ DDI for Category 1 CS. A delay was universal. The DDI of 30-75 min for Category 2 CS could be achieved in $61.11 \%$ cases. The most common reason for failure to achieve the recommended DDI was related to issues with anesthesia in the preoperative room as well as inside the theatre, in the preinduction phase. Delay in Category 2 CS was not associated with poor perinatal outcome.

\section{REFERENCES}

1. National Institute for Health and Care Excellence (2011) Caesarean Section. NICE guideline. (CG 132) Available from: https://www.nice.org.uk/guidance/ng192

2. Bruce $D$, Stone $S$ and Harding K. Evaluation of emergency caesarean sections--completion of the audit cycle in a Central London teaching hospital. J Obstet Gynaecol. 2002; 22(3):273-278. https://doi.org/10.1080/01443610220130553

3. Helmy WH, Jolaoso AS, Ifaturoti OO, Afify SA and Jones MH. The decision-to-delivery interval for emergency caesarean section: is 30 min a realistic target? BJOG. 2002; 109(5):505-508.

https://doi.org/10.1111/j.1471-0528.2002.00491.x

4. Livermore LJ and Cochrane RM. Decision to delivery interval: a retrospective study of 1,000 emergency caesarean sections. J Obstet Gynaecol. 2006; 26(4):307-310. https://doi.org/10.1080/01443610600594898

5. Hirani BA, Mchome BL, Mazuguni NS and Mahande MJ. The decision delivery interval in emergency caesarean section and its associated maternal and fetal outcomes at a referral hospital in northern Tanzania: a cross-sectional study. BMC Pregnancy and Childbirth. 2017; 17: 411 
https://doi.org/10.1186/s12884-017-1608-x

6. Owonikoko KM, Olabinjo AO, BelloAjao HT, Adeniran MA and Ajibola TA. Determinants of Decision to Delivery Interval (DDI) in Emergency Caesarean Sections in Ladoke Akintola University Of Technology Teaching Hospital Ogbomoso, Nigeria. Ann Pregnancy Birth. 2018; 1(1): 1001.

7. Khemworapong $\mathrm{K}$, Sompagdee $\mathrm{N}$ and Boriboonhirunsarn $\mathrm{D}$. Decision-to-delivery interval in emergency cesarean delivery in tertiary care hospital in Thailand. Obstet Gynecol Sci. 2018;61(1):48-55.

https://doi.org/10.5468/ogs.2018.61.1.48

8. Kamotho D, Pertet AM and Ogwayo I. Decision to incision interval for emergency caesarean section and postoperative outcomes in a resource limited rural Kenyan public hospital. Int J Reprod Contracept Obstet Gynecol. 2018; 7(7): 2573-2578.

https://doi.org/10.18203/2320-1770.ijrcog20182863

9. Singh R, Deo S and Pradeep Y. The decision-to-delivery interval in emergency Caesarean sections and its correlation with perinatal outcome: evidence from 204 deliveries in a developing country. Trop Doct. 2012;42(2):67-69.

https://doi.org/10.1258/td.2012.110315

10. Nair VV, Nair SS and Venugopalan P. Decision to delivery interval in emergency LSCS and its impact on fetal outcome. Int J Reprod Contracept Obstet Gynecol. 2019; 8(9):3679-3683.

https://doi.org/10.18203/2320-1770.ijrcog20193797
11. Dunn CN, Zhang Q, Sia JT, Assam PN, Tagore S and Sng BL. Evaluation of timings and outcomes in category-one caesarean sections: A retrospective cohort study. Indian J Anaesth 2016; 60:546-551.

https://doi.org/10.4103/0019-5049.187782

12. Radhakrishnan G, Yadav G, Vaid NB and Ali H. Factors affecting 'decision to delivery interval' in emergency cesarean sections in a tertiary care hospital: a cross sectional observational study. Int J Reprod Contract Obstet Gynecol. 2013; 2(4):651-656. https://doi.org/10.5455/2320-1770.jircog20131231

13. Brandt J-A, Morgenstern B, Thangarajah F, GrÜttner B, Ludwig S, Eichler C, et al. Evaluating the Decision-to-Delivery Interval in Emergency Caesarean sections and its Impact on Neonatal Outcome. In vivo. 2020; 3341-3347. https://doi.org/10.21873/invivo.12172

14. Rashid $\mathrm{N}$ and Nalliah $\mathrm{S}$. Understanding the decision to delivery interval in cesarean births. Int EJ Sci Med Educ. 2007; 1:61-68.

15. Yakasai IA, Ahmed ZD and Okonofua FE. Decision delivery interval in emergency cesarean section in tertiary centre in Northern Nigeria. Orient J Sci Res. 2012; 1:16-23.

16. Boriboonhirunsarn $\mathrm{D}$, Watananirun $\mathrm{K}$ and Sompagdee $\mathrm{N}$. Decision-to-delivery interval in pregnant women with intrapartum non-reassuring fetal heart rate patterns. J Eval Clin Pract. 2016; 22(6):998-1002.

https://doi.org/10.1111/jep.12613

\section{Authors Contribution:}

FK-Concept and design of the study, drafting of manuscript; AA-Interpret results, manuscript preparation and submission; AS, SS-Data collection, reviewed literature; NT-Data extraction, analysis and statistical analysis. All authors read and approved the final manuscript.

Work attributed to:

Department of Obstetrics and Gynaecology, Era's Lucknow Medical College and Hospital, Uttar Pradesh, India.

Orcid ID:

Dr. Fareha Khatoon- (1) https://orcid.org/0000-0002-0084-9528

Dr. Amrita Singh- (i) https://orcid.org/0000-0002-2462-9706

Dr. Sumaiyya Shamsi- (D) https://orcid.org/0000-0001-7373-6340

Dr. Ayesha Ahmad- (i) https://orcid.org/0000-0003-2324-158X

Dr. Nikunj Teotia- (i) https://orcid.org/0000-0002-6405-154X

Source of Funding: None, Conflict of Interest: None. 